\title{
Conservation of endangered Tipton kangaroo rats (Dipodomys nitratoides nitratoides): status surveys, habitat suitability, and conservation recommendations
}

\author{
BRIAN L. CYPHER ${ }^{1 *}$, SCOTT E. PHILLIPS ${ }^{1}$, TORY L. WESTALL ${ }^{1}$, \\ ERIN N. TENNANT ${ }^{1,2}$, LAWRENCE R. SASLAW ${ }^{1}$, ERICA C. KELLY ${ }^{1}$, \\ AND CHRISTINE L. VAN HORN JOB ${ }^{1,3}$
}

${ }^{1}$ California State University-Stanislaus, Endangered Species Recovery Program, One University Circle, Turlock, CA 95382, USA

${ }^{2}$ Current address: California Department of Fish and Wildlife, Central Region, Lands Unit, 1234 E. Shaw Ave, Fresno, CA 93710, USA

${ }^{3}$ Current address: McCormick Biological, Inc., P.O. Box 80983, Bakersfield, CA 93380, USA
*Corresponding Author: bcypher@esrp.csustan.edu

The Tipton kangaroo rat (Dipodomys nitratoides nitratoides; TKR) is listed as endangered both Federally and by the state of California due to profound habitat loss throughout its range in the southern San Joaquin Valley of California. Habitat loss is still occurring and critical needs for TKR include identifying occupied sites, quantifying optimal habitat conditions, and conserving habitat. Our objectives were to (1) conduct surveys to identify sites where TKR were extant, (2) assess habitat attributes on all survey sites, (3) generate a GIS-based model of TKR habitat suitability, (4) use the model to determine the quantity and quality of remaining TKR habitat, and (5) use these results to develop conservation recommendations. We surveyed for TKR on 44 sites by live-trapping and detected TKR on 15 sites. Sites with TKR tended to have larger alkali scalds and no obvious sign of past tilling compared to sites without TKR. Also, sites with TKR usually had relatively sparse ground cover and seepweed (Suaeda nigra) was present. The non-protected Heermann's kangaroo rat (Dipodomys heermanni), a larger competitor, was either absent or present in relatively low numbers at sites with TKR, and when present its abundance was inversely related to that of TKR. Based on our habitat suitability modeling, an estimated 30,000 ha of moderately high or high quality TKR habitat and 60,000 ha of lower or medium quality habitat remain. However, habitat is still being lost and conversion of at least one survey site with TKR occurred during this project. Recommendations for TKR conservation are to (1) conduct additional TKR surveys on unsurveyed but suitable sites, (2) conserve suitable habitat on unprotected lands, (3) manage vegeta- 
tion on occupied sites if necessary, (4) restore disturbed lands to increase suitability for TKR, and (5) research methods and conduct translocations of TKR to unoccupied sites with suitable habitat.

Key words: conservation, Dipodomys nitratoides nitratoides, endangered, habitat suitability, San Joaquin Valley, status survey, Tipton kangaroo rat

The Tipton kangaroo rat (Dipodomys nitratoides nitratoides: TKR) is one of three subspecies of the San Joaquin kangaroo rat that is endemic to the San Joaquin Valley in central California (Best 1991; USFWS 1998). TKR once were widely distributed on the valley floor from about the Kings River in Kings County south to the southern end of the valley in Kern County (Fig. 1). They occur in arid scrub habitats on the valley floor, but much of this habitat has been converted to agricultural, urban, and industrial uses (USFWS 1998). By 1985, only an estimated 3.7\% of historical habitat remained, and many of these lands consisted of small, isolated fragments of varying quality (Williams and Germano 1992). None of the remaining occupied habitat patches likely exceed 2,000 ha in size (USFWS 2010). Due to this profound habitat loss, fragmentation, and degradation, TKR were Federally listed as Endangered in 1988 and California-listed as Endangered in 1989 (USFWS 1998).

As of the early 2000s, TKR were known to persist at a number of locations (USFWS 2010). However, habitat loss is still occurring throughout the range of TKR and this continuing loss threatens to extirpate existing populations and could even preclude recovery. A critical conservation need is to locate remaining populations and also to identify suitable habitat so that efforts can be optimized for conserving and recovering of TKR.

Specific habitat attribute preferences for TKR are poorly quantified. According to the recovery plan that includes TKR (USFWS 1998), they are limited to arid-land communities with level or nearly level terrain. Furthermore, the plan states that shrubs typically present include spiny saltbush (Atriplex spinifera), desert saltbush (Atriplex polycarpa), arrowscale (Atriplex phyllostegia), quailbush (Atriplex lentiformis), iodine bush (Allenrolfea occidentalis), pale-leaf goldenbush (Isocoma acradenia), and honey mesquite (Prosopis glandulosa). Seepweed (Suaeda nigra [= moquinii]) is described as a "conspicuous semiwoody species" in areas with TKR. Shrub cover typically is sparse to moderate in areas with high TKR density. Because flat terrain on the valley floor is subject to flooding, some microtopography is considered important as it provides refugia during flood events. Finally, higher densities of TKR tend to occur on soils with higher salinity (USFWS 1998).

Optimal habitat attributes for TKR have not been determined. Spatially-explicit habitat suitability modeling is a powerful tool for determining suitable habitat attributes and identifying specific lands that possess those attributes. Such lands then can be targeted for protection, and conservation actions such as surveys, monitoring, and reintroductions can be considered as appropriate.

The goal of this project was to generate information and tools that will significantly enhance TKR conservation and recovery efforts. Specific objectives were to (1) conduct surveys throughout the range to identify sites where TKR were extant, (2) assess habitat attributes on all survey sites, (3) use the attribute data from sites with and without TKR to generate a GIS-based model of TKR habitat suitability, (4) extend the model across the TKR range to determine the quantity and quality of remaining habitat, and (5) use the findings from the above tasks to develop conservation recommendations. 


\section{METHODS}

\section{Study Area}

The study area for this project was the historic range of TKR (Fig. 1). This area is within the region known as the San Joaquin Desert (Germano et al. 2011). The regional climate is Mediterranean in nature, and is characterized by hot, dry summers, and cool, wet winters with frequent fog. Mean maximum and minimum temperatures are $35^{\circ} \mathrm{C}$ and $18^{\circ} \mathrm{C}$

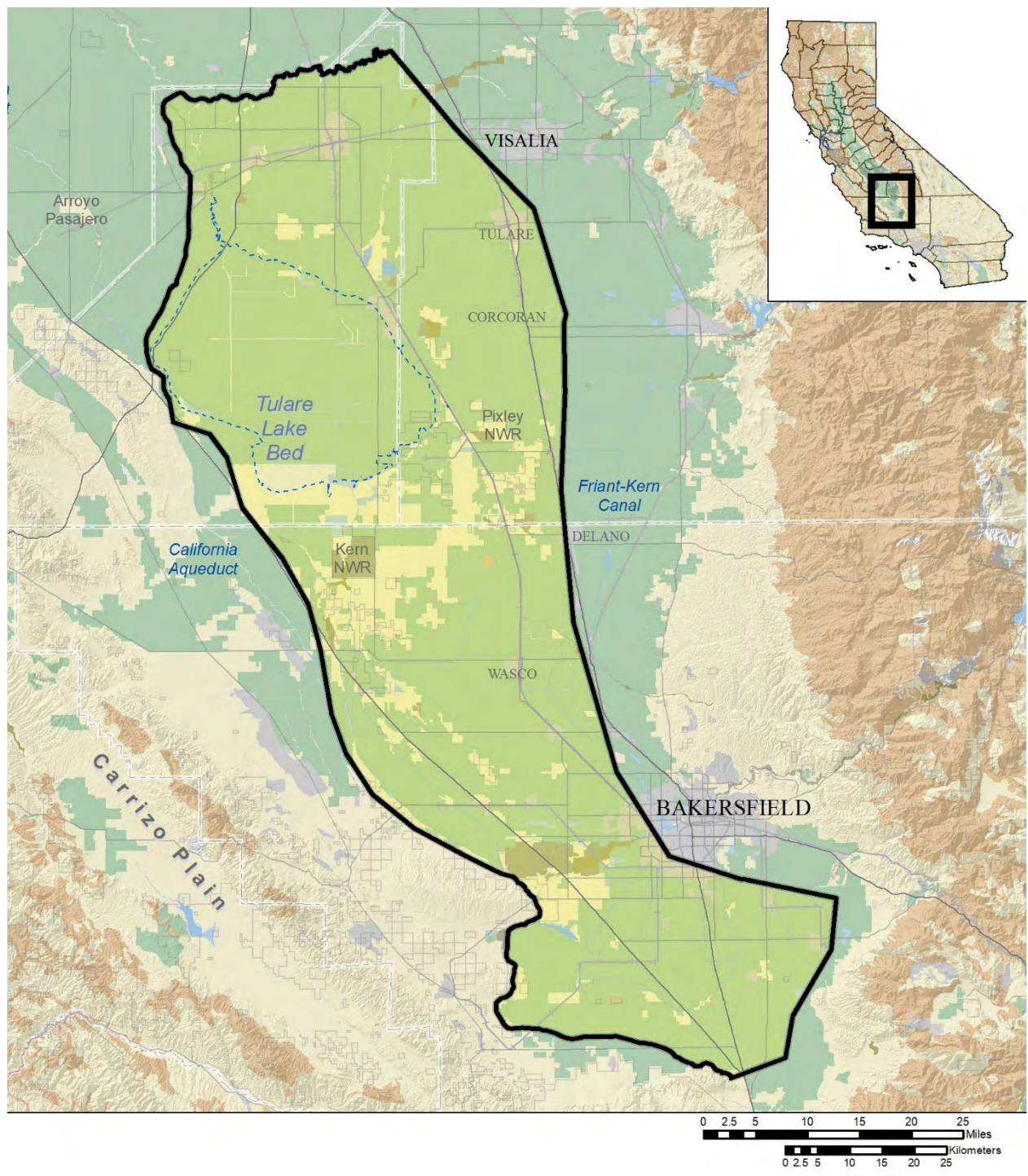

Approximate historical Tipton kangaroo rat range

Figure 1. Historic range of the Tipton kangaroo rat in the San Joaquin Valley, California, USA. 
in summer, and $17^{\circ} \mathrm{C}$ and $5^{\circ} \mathrm{C}$ in winter. Annual precipitation averages about $15 \mathrm{~cm}$ and occurs primarily as rain falling between October and April (NOAA 2002).

Most of the region within the TKR range is largely flat valley bottom land with elevations generally around $100 \mathrm{~m}$. Vegetation is characterized by desert scrub habitat on the upland sites and alkali sink habitat on the valley floor. Historically, there were riparian corridors along rivers and creeks that carried runoff water from the Sierra Nevada into the valley. This water collected in shallow lakes that were surrounded by seasonal wetlands (Griggs et al. 1992). Most of the riparian and wetland habitats have been drained and large proportions of the desert scrub and alkali sink habitats also have disappeared due to conversion of natural lands to agricultural, industrial, and urban uses (USFWS 1998; Kelly et al. 2005).

\section{TKR Surveys}

To identify locations for TKR surveys, we conducted an initial habitat suitability analysis using existing information. We consulted with colleagues who had conducted small mammal surveys in the southern San Joaquin Valley to identify sites where TKR had been detected. Some of these sites were long-term monitoring plots; these sites were particularly valuable because TKR were both present and persistent over time (i.e., $>20$ years). We qualitatively categorized sites based on TKR abundance and persistence. High quality sites were those where multiple TKR were captured during individual trapping sessions and where TKR were consistently present based on annual monitoring or repeated surveys. "Medium" quality sites were those where only one or two TKR were captured during a given trapping session or where TKR were only intermittently detected based on annual monitoring or repeated surveys. Low quality sites were those where surveys or annual monitoring was conducted but no TKR had been detected.

Based on the criteria above, we identified 8 high quality sites, 8 medium quality sites, and 8 low quality sites. We then assessed two habitat attributes, land use and the amount of bare ground, on each of the sites using remotely sensed data layers. We used current GIS land use layers to identify lands that had not been converted to agricultural, urban, or industrial uses (USGS 2007; CDOC 2012; CDWR 2012). On undeveloped lands of 4 ha (10 acre) or more, we estimated the amount of peak growing season bare ground cover using the Web-Enabled Landsat Data, Peak growing season Bare Ground cover per 30m pixel dataset (USGS 2013). Based on this analysis, low quality areas had $<29 \%$ bare ground, medium quality areas had $29-42 \%$ bare ground, and high quality areas had $42-60 \%$ bare ground. Areas with $>60 \%$ bare ground appeared to be highly disturbed by oil development or disking and were not considered to be TKR habitat. These results were applied across the TKR range to produce a preliminay map of habitat suitability. Using this map, we selected sites within high and medium suitability areas to survey for TKR, assuming that we would have the highest probability of finding new populations on these sites.

The specific sites we chose to survey were those for which access was granted by the landowner and where no recent surveys (past 5 years) had been conducted. On these sites, we surveyed for TKR by live-trapping. On most sites, two lines of 15 or 20 traps each were set (the number of traps depended upon the amount of potential habitat on a given site). The lines generally meandered so that traps could be set close to areas with kangaroo rat activity (e.g., active burrows, fresh scats, dust baths). We used Sherman aluminum box traps (7.6 x 9.5 x $30.5 \mathrm{~cm}$; H. B. Sherman Traps Inc., Tallahassee, FL) modified to prevent injury to the long tails of kangaroo rats. Traps were spaced 10-15 m apart, opened around sunset, 
baited with white millet bird seed, and provisioned with a paper towel for bedding material. Traps were checked the next morning around sunrise. Captured animals were identified to species, age and sex were recorded, and then animals were marked on their ventral side with a non-toxic felt-tipped marker to identify recaptures. A site was considered to be occupied by TKR if any TKR were captured during the trapping session.

We trapped on most sites for just two nights. Prior experience by our team as well as that of colleagues indicated that this would be sufficient to detect TKR. In 79 trapping sessions on 5 long-term monitoring grids with high quality habitat in the Semitropic Ridge area in northern Kern County, TKR were detected in $100 \%$ of the sessions after just one night of trapping (G. Warrick, Center for Natural Lands Management [CNLM], personal communication). Even on one grid with lower quality habitat, TKR were detected in $75 \%$ of 12 sessions after one night of trapping and in $92 \%$ of the sessions after two nights. Similarly, in 32 trapping sessions on 4 long-term monitoring grids on the Coles Levee Ecosystem Preserve in western Kern County, TKR were detected in $84 \%$ of the sessions after one night of trapping and in $97 \%$ of the sessions after two nights (J. Jones, South Valley Biology, personal communication). Thus, when present, detection rates for TKR tend to be high in just one or two nights of trapping, even in lower quality habitat where TKR density may be lower.

\section{Habitat Attributes}

At each site that we surveyed for TKR, a suite of habitat attributes was characterized and recorded (Table 1). We recorded information on alkali scalds (which are common features in alkali sink habitat), shrubs, ground cover, anthropogenic disturbances, microtopography, and distance to active agriculture. Much of this information was qualitative so that the survey sites could be characterized quickly (ca. $15 \mathrm{~min}$ ). For shrubs, iodine bush and seepweed are commonly associated with TKR habitat (USFWS 1998) and so the presence of these species was of particular interest. For categorical variables, frequencies were compared between sites with and without TKR using contingency table analyses with a Yate's correction for continuity applied to $2 \times 2$ analyses.

To further explore variables that might affect TKR presence and abundance, we compared the frequency of the presence of Heermann's kangaroo rats (D. heermanni; HKR) between sites with and without TKR using $2 \times 2$ contingency table analyses with a Yate's correction for continuity. We also compared the mean number of HKR captured per 100 trapnights between sites with and without TKR using a paired $t$-test. Finally, for sites where TKR were present, we used linear regression analysis to examine the relationship between TKR and HKR abundance (number per 100 trapnights). Because of the presence of a number of zero values for HKR abundance, a square root transformation was applied to the data to correct normality prior to conducting the regression analysis (Zar 1984). Statistical tests were conducted using Excel (Microsoft Excel v. 2010) or Social Science Statistics (2020). $P$-values $\leq 0.05$ were considered significant.

\section{Habitat Suitability Modeling}

We used information on land condition and habitat attributes from the surveys (Table 1, see RESULTS) to produce a model and map of TKR habitat suitability. In particular, information on land use, disturbances, ecological community, and ground cover were incorporated into the model. We used GIS land use layers (USGA 2007; CDOC 2012; CDWR 2012) to identify undeveloped lands. Lands developed for agricultural, urban, or 
Table 1. Habitat attributes assessed on sites surveyed for Tipton kangaroo rats in the southern San Joaquin Valley, California, USA.

\begin{tabular}{ll}
\hline Attribute & Measure \\
\hline Alkali scalds & Present/absent \\
Average size of scalds if present & Large: $>36 \mathrm{~m}^{2}$ \\
& Medium: $6-36 \mathrm{~m}^{2}$ \\
& Small: $<6 \mathrm{~m}^{2}$ \\
Shrubs & Present/absent \\
Average shrub density if present & Dense: $<2 \mathrm{~m}$ apart \\
& Medium: $2-10 \mathrm{~m}$ apart \\
Shrub species & Sparse: $>10 \mathrm{~m}$ apart \\
Average ground cover density & List of species present \\
& Dense: $<10 \%$ bare ground \\
& Medium: $10-29 \%$ bare ground \\
Ground cover species & Sparse: $>29 \%$ bare ground \\
Anthropogenic disturbances & List of species with $>10 \%$ cover \\
& List all present (e.g., OHV, tilling, trash \\
Microtopography & dumping, excavations, etc.) \\
& Generally flat \\
Distance to active agriculture & Undulations $<25 \mathrm{~cm}$ tall \\
\hline
\end{tabular}

industrial uses were considered non-habitat for TKR and were not included in the analysis. All undeveloped lands were assigned a habitat suitability rank from 1 to 4 with 1 being the highest quality habitat and 4 being the lowest. Among undisturbed lands, we used the layer described previously (USGS 2013) to estimate mean percentage of bare ground. Map units with a mean percentage of bare ground $>29 \%$ were assigned to Rank 1 if the vegetation community was classified as alkali sink, or to Rank 2 if the vegetation community was classified as non-alkali sink rangelands. Undisturbed map units with a mean percentage of bare ground $<29 \%$ were assigned to Rank 3 . Lands with evidence of recent disturbance, such as disking or flooding, were assigned to Rank 4.

\section{RESULTS}

\section{TKR Surveys}

We conducted surveys on 44 sites (Fig. 2). Most of the surveys were conducted during October 2013-May 2014. Information from four additional survey efforts conducted in November 2012, October 2014, and March 2015 also were included in our analyses. Of these 44 surveys, 32 were on California Department of Fish and Wildlife (CDFW) lands, 5 were on private lands, and 7 were on federal conservation lands (Pixley National Wildlife Refuge, U.S. Bureau of Land Management). TKR were captured on 15 sites, and were not 
detected on 29 sites (Fig. 2). TKR had not been previously known to occur on 8 of the 15 sites where they were detected.

\section{Habitat Attributes}

Habitat attribute data were collected at all sites surveyed for TKR (Table 2). Significant differences between sites with and without TKR were not detected for most attributes. However, sites with TKR tended to have larger sized scalds (Table 2). Obvious signs of past tilling were present on a greater proportion of sites without TKR (75.9\%) compared to sites with TKR (7.7\%; Table 2).

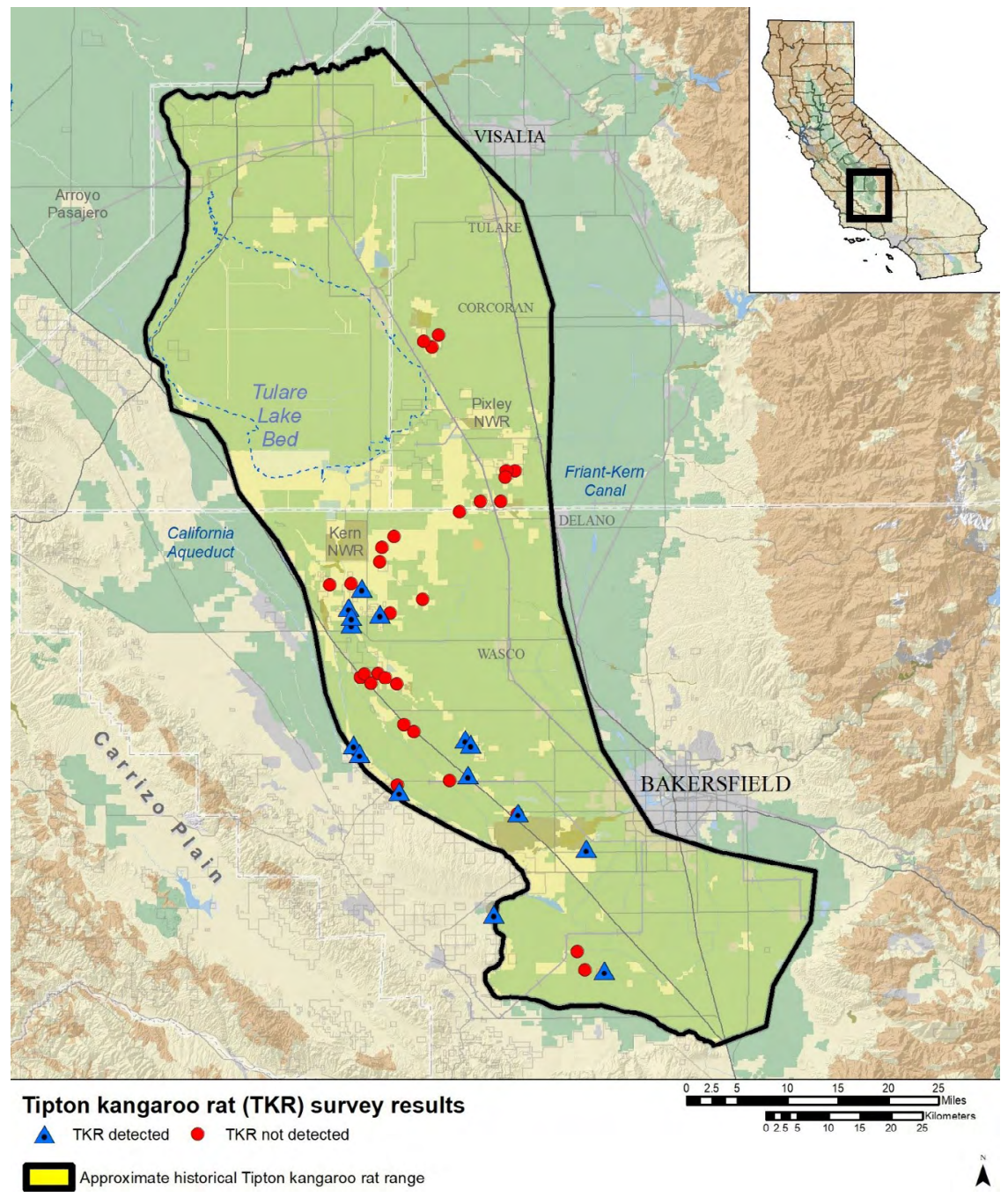

Figure 2. Sites $(n=44)$ surveyed for Tipton kangaroo rats in the southern San Joaquin Valley, California, USA. 
HKR were present on a significantly lower proportion $\left(\chi^{2}=4.32, p=0.04\right)$ of sites with TKR $(53.3 \%)$ compared to sites without TKR $(82.8 \%)$. The mean ( \pm SE) number of HKR captured per 100 trap-nights was significantly lower $\left(t_{40}=-2.73, p=<0.01\right)$ on sites with TKR $(1.8 \pm 0.6)$ compared to sites without TKR $(4.2 \pm 0.7)$. On sites with TKR, the number of TKR captured per 100 trap-nights was negatively related $\left(F_{1,13}=6.10, p=0.03\right.$, $\left.r^{2}=0.32\right)$ to the number of HKR captured per 100 trap-nights.

\section{Habitat Suitability Modeling}

Based on the TKR habitat suitability modeling, we identified approximately 30,000 ha (Table 3, Fig. 3) that were high or moderately high quality (Rank 1 or 2 ) habitat. We identified an additional 20,000 ha of medium quality (Rank 3) and about 40,000 ha of low quality (Rank 4) habitat.

\section{DISCUSSION}

\section{TKR Occurrence and Distribution}

The TKR surveys we conducted had some inherent limitations. Most of the surveys (93\%) were only conducted for a maximum two nights, although for reasons stated in the methods, we felt that this usually was sufficient for detecting TKR. In addition to a limited number of trap nights at each site, we did not survey most sites in their entirety. A number of the sites were quite large (several hundred hectares) and we typically selected areas to trap where the habitat seemed to be in good condition and particularly where kangaroo rat activity was present. However, TKR could have been present in portions of sites that we did not trap. Also, most of our surveys were conducted in 2013 and 2014 when precipitation was below average and regional kangaroo rat populations generally were declining (G. Warrick, CNLM, unpublished data; E. Tennant, CDFW, unpublished data). Thus, TKR may have been present on some sites we surveyed, but in low density or patchy distributions, both of which would inhibit detection. Finally, we were not able to survey in many locations with potential TKR habitat because the sites were private lands and access was not granted.

For the reasons given above, our survey results should not be considered definitive, although when combined with trapping results by others, the cumulative findings provide an informative assessment of the current distribution of sites where TKR are extant. We detected TKR at 15 sites (see Fig. 2). We also examined results of TKR trapping survey and monitoring efforts conducted during the past 20 years. These results were provided by colleagues (G. Warrick, CNLM; J. Jones, South Valley Biology; D. Germano, California State University-Bakersfield; C. Uptain, QuadKnopf) and also by the USFWS permit office in Sacramento, CA, and they yielded additional sites where TKR have been detected. At some sites, natural habitat is no longer present based on Google Earth imagery. Disregarding these sites, another 51 sites were identified where TKR presumably still occur. These detections in combination with those from our surveys resulted in 66 sites (Fig. 4) where TKR were potentially extant as of 2017 .

An important caveat is that the 66 sites do not equate to populations of TKR. A number of these sites were separated by $<1 \mathrm{~km}$ of contiguous habitat. In some cases, different portions of the same site were surveyed but at different times. In other cases, multiple monitoring grids were located within a population area, such as occurred in the Coles Levee Ecosystem Preserve ( 9 grids) and Semitropic Ridge area ( 8 grids). Consequently, even though 66 sites 
Table 2. Habitat attributes on sites with and without Tipton kangaroo rat detections during surveys conducted in the southern San Joaquin Valley, California, USA.

\begin{tabular}{|c|c|c|c|}
\hline Attribute & $\begin{array}{l}\text { Sites w/ TKR } \\
\quad(n=15)\end{array}$ & $\begin{array}{l}\text { Sites w/o TKR } \\
\quad(n=29)\end{array}$ & Statistical tests \\
\hline Scalds present & $\begin{array}{l}\text { Yes: } 12(80.0 \%) \\
\text { No: } 3(20.0 \%)\end{array}$ & $\begin{array}{l}\text { Yes: } 25(86.2 \%) \\
\text { No: } 4(13.8 \%)\end{array}$ & $\begin{array}{c}\chi^{2}=0.28,1 \mathrm{df} \\
p=0.59\end{array}$ \\
\hline Scald size & $\begin{array}{l}\text { Large: } 9(75.0 \%) \\
\text { Medium: } 1(8.3 \%) \\
\text { Small: } 2(16.7 \%)\end{array}$ & $\begin{array}{c}\text { Large: } 8(32.0 \%) \\
\text { Medium: } 13(52.0 \%) \\
\text { Small: } 6(24.0 \%)\end{array}$ & $\begin{array}{c}\chi^{2}=7.72,1 \mathrm{df} \\
p=0.02\end{array}$ \\
\hline Shrubs present & $\begin{array}{c}\text { Yes: } 15(100 \%) \\
\text { No: } 0(0.0 \%)\end{array}$ & $\begin{array}{c}\text { Yes: } 29(100 \%) \\
\text { No: } 0(0.0 \%)\end{array}$ & - \\
\hline Shrub density & $\begin{array}{c}\text { Dense: } 1(6.7 \%) \\
\text { Medium: } 10(66.6 \%) \\
\text { Sparse: } 4(26.7 \%)\end{array}$ & $\begin{array}{c}\text { Dense: } 3(10.3 \%) \\
\text { Medium: } 15(51.7 \%) \\
\text { Sparse: } 11(38.0 \%)\end{array}$ & $\begin{array}{c}\chi^{2}=0.90,2 \mathrm{df} \\
p=0.64\end{array}$ \\
\hline Iodine bush present & $\begin{array}{l}\text { Yes: } 6(40.0 \%) \\
\text { No: } 9(60.0 \%)\end{array}$ & $\begin{array}{l}\text { Yes: } 8(27.6 \%) \\
\text { No: } 21(72.4 \%)\end{array}$ & $\begin{array}{c}\chi^{2}=0.70,1 \mathrm{df} \\
p=0.40\end{array}$ \\
\hline Sinkweed present & $\begin{array}{l}\text { Yes: } 11(73.3 \%) \\
\text { No: } 4(26.7 \%)\end{array}$ & $\begin{array}{l}\text { Yes: } 21(72.4 \%) \\
\text { No: } 8(27.6 \%)\end{array}$ & $\begin{array}{c}\chi^{2}<0.01,1 \mathrm{df} \\
p=0.95\end{array}$ \\
\hline Ground cover density & $\begin{array}{c}\text { Dense: } 1(6.7 \%) \\
\text { Medium: } 2(13.3 \%) \\
\text { Sparse: } 12(80.0 \%)\end{array}$ & $\begin{array}{c}\text { Dense: } 3(10.3 \%) \\
\text { Medium: } 11(38.0 \%) \\
\text { Sparse: } 15(51.7 \%)\end{array}$ & $\begin{array}{c}\chi^{2}=3.46,2 \mathrm{df} \\
p=0.18\end{array}$ \\
\hline Presently grazed & $\begin{array}{l}\text { Yes: } 8(53.3 \%) \\
\text { No: } 7(46.7 \%)\end{array}$ & $\begin{array}{l}\text { Yes: } 22(75.9 \%) \\
\text { No: } 7(24.1 \%)\end{array}$ & $\begin{array}{c}\chi^{2}=2.31,1 \mathrm{df} \\
p=0.13\end{array}$ \\
\hline Previous tilling & $\begin{array}{c}\text { Yes: } 1(7.7 \%) \\
\text { No: } 14(92.3 \%)\end{array}$ & $\begin{array}{l}\text { Yes: } 22(75.9 \%) \\
\text { No: } 7(24.1 \%)\end{array}$ & $\begin{array}{c}\chi^{2}=18.97,1 \mathrm{df} \\
p<0.01\end{array}$ \\
\hline Microtopography & $\begin{aligned} & \text { Flat: } 5(33.4 \%) \\
\leq 30 \mathrm{~cm}: & 8(53.4 \%) \\
> & 30 \mathrm{~cm}: 2(13.3 \%)\end{aligned}$ & $\begin{array}{c}\text { Flat: } 3(10.3 \%) \\
\leq 30 \mathrm{~cm}: 18(62.1 \%) \\
>30 \mathrm{~cm}: 8(27.6 \%)\end{array}$ & $\begin{array}{c}\chi^{2}=3.88,2 \mathrm{df} \\
p=0.14\end{array}$ \\
\hline $\begin{array}{l}\text { Mean distance to ag- } \\
\text { riculture }\end{array}$ & $0.77 \pm 0.07 \mathrm{~km}$ & $0.61 \pm 0.07 \mathrm{~km}$ & $\begin{array}{c}t=-0.88,31 \mathrm{df} \\
p=0.19\end{array}$ \\
\hline
\end{tabular}

with TKR were identified, the number of actual populations clearly is $<66$, depending upon how "populations" are delineated.

Sites with TKR were distributed throughout the historic range of TKR (Fig. 4). More sites were extant on the western side of the San Joaquin Valley because a larger proportion of the habitat on the eastern and central portions of the valley has been converted to agricultural and other incompatible uses or not managed appropriately for TKR. Furthermore, TKR habitat is still being converted. As mentioned previously, several sites where TKR were detected in the past 20 years no longer have natural habitat, and one of our survey sites was disked in preparation for development within three months after we completed our survey. Consequently, the number of extant TKR populations continues to decline.

The distribution of sites with TKR has advantages and disadvantages for conservation. An advantage is that the sites were widely dispersed. This reduces the risk to the overall TKR 
Table 3. Amount of remaining habitat by suitability rank for the Tipton kangaroo rat in the southern San Joaquin Valley, California, USA. Other habitats include saltbush scrub and grassland. Disturbed habitat was defined as previously tilled.

\begin{tabular}{lccccc}
\hline Land use & Disturbance & \% Barren & Vegetation & Habitat rank & Area (ha) \\
\hline Rangeland & Undisturbed & $>29 \%$ & Alkali sink & 1 & $21,267(24 \%)$ \\
& Undisturbed & $>29 \%$ & Other habitat & 2 & $8,446(9 \%)$ \\
& Undisturbed & $\leq 29 \%$ & Any habitat & 3 & $20,592(23 \%)$ \\
& Disturbed & Variable & Any habitat & 4 & $39,621(44 \%)$ \\
Total & & & & & 89,926 \\
\hline
\end{tabular}

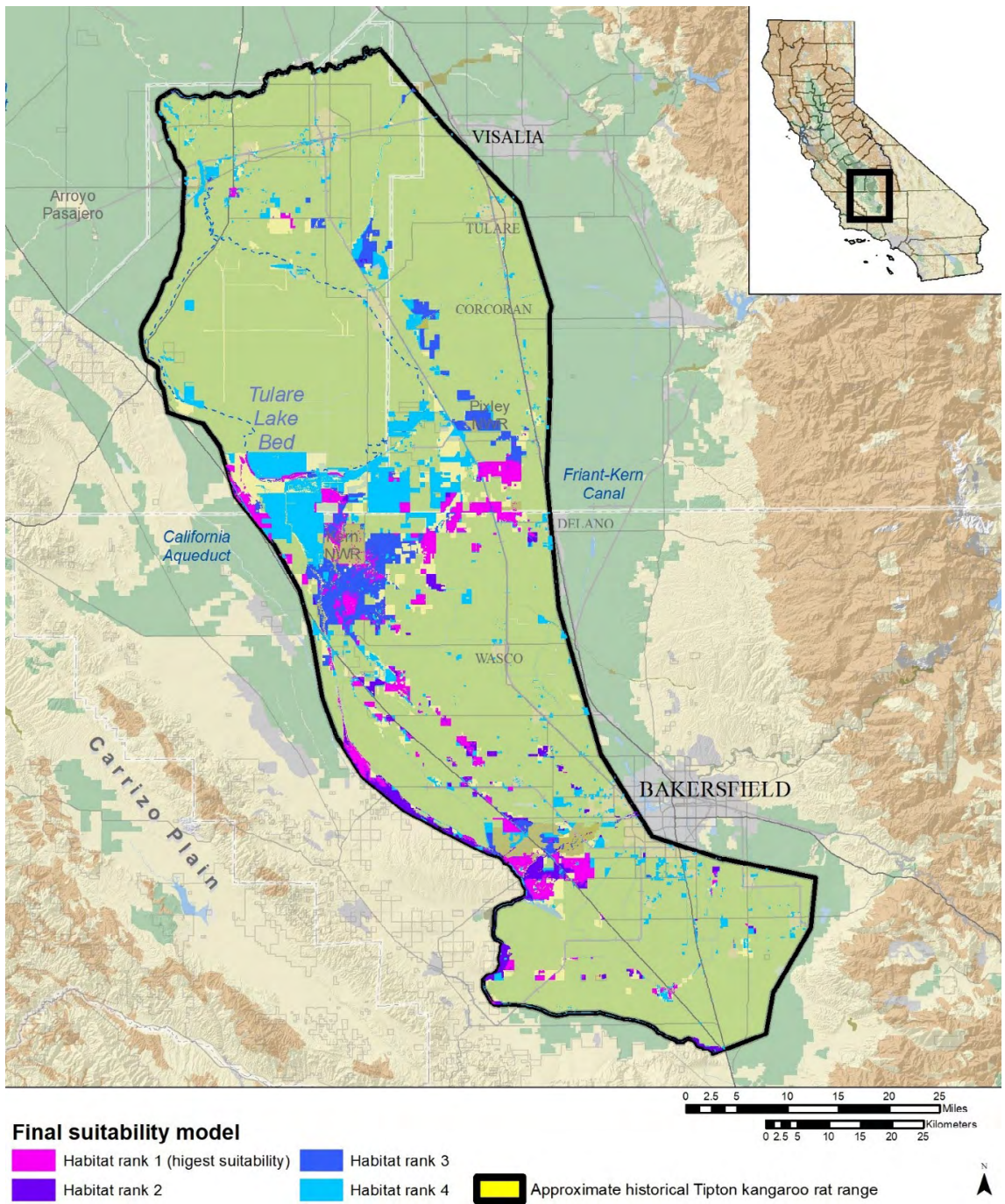

Figure 3. Results of habitat suitability modeling analysis for the Tipton kangaroo rat. 
population from localized catastrophic events such as flooding, fires, or disease. Flooding in the 1990s may have been responsible for the extirpation of the TKR population at Pixley National Wildlife Refuge (California State University-Stanislaus, Endangered Species Recovery Program, unpublished data) and significant reduction of the population at Allensworth Ecological Reserve (CDFW, unpublished data). The dispersed sites also increase the probability that when such catastrophic events occur, some populations will not be affected and could serve as source populations for reintroduction efforts. A disadvantage of the widely distributed sites is that in the event of local extirpation resulting from catastrophic or stochastic events, recolonization is highly unlikely without anthropogenic assistance.

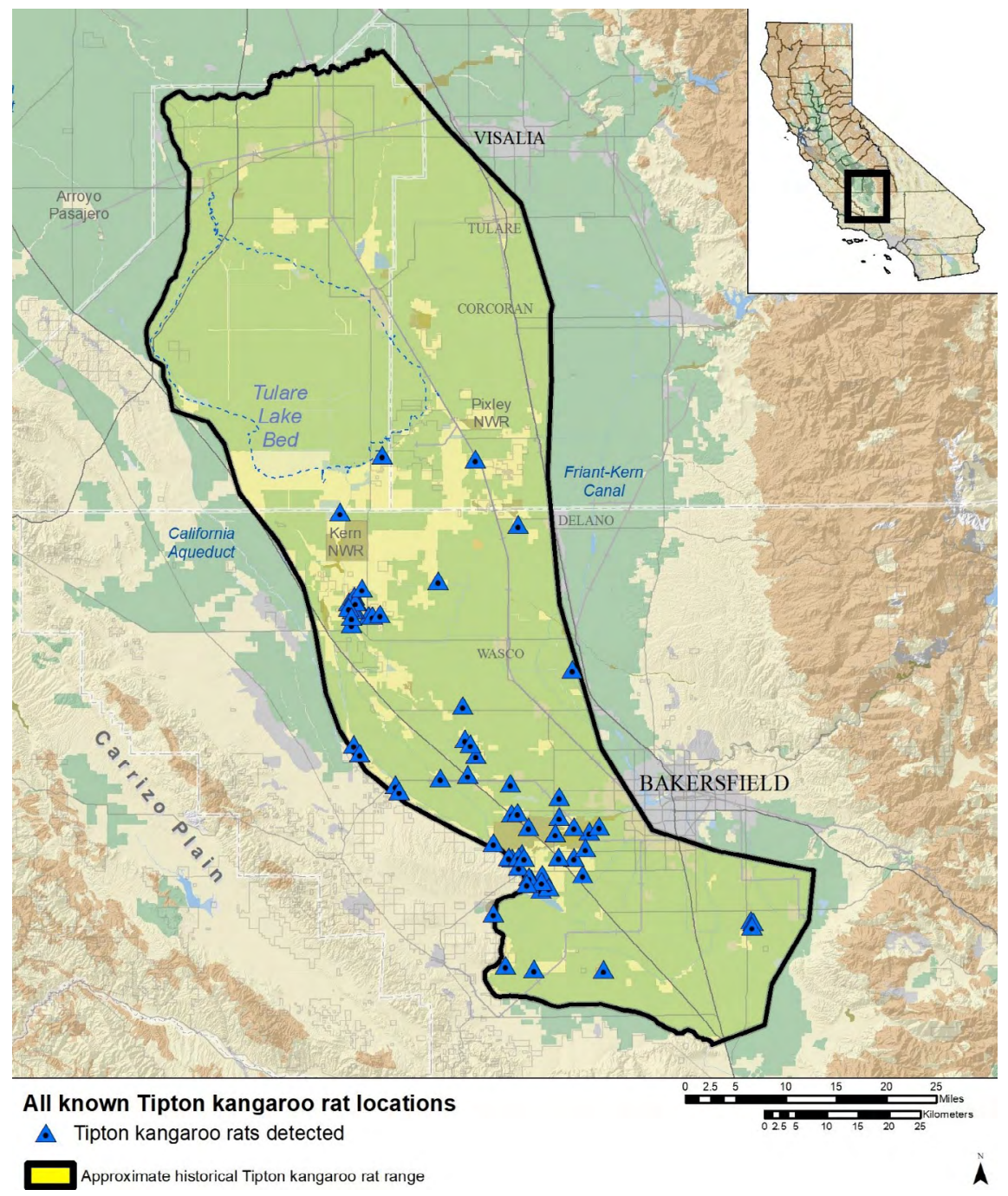

Figure 4. Total sites $(n=66)$ from previous efforts and from this study where Tipton kangaroo rats were detected and were assumed to be extant as of 2017 in the southern San Joaquin Valley, California, USA. 


\section{Habitat Attributes}

Based on the habitat description for TKR from the recovery plan (USFWS 1998) that was provided in the Introduction, as well as our previous survey experiences along with that of other researchers, we had specifically targeted sites with alkali sink habitat (e.g., alkaline playas with seepweed or iodine bush present) for surveys, but we surveyed sites with other habitat conditions as well. Generally, sites where TKR were detected usually had good quality alkali sink habitat, consistent with the habitat description in the recovery plan (USFWS 1998). The larger alkali scalds present on sites with TKR likely were indicators of good quality alkali sink habitat. The scalds themselves are not likely used extensively by TKR. We rarely found burrows in the scalds and there was little or no vegetation to provide a food source or cover.

A significant finding was that TKR rarely were found on sites with evidence of past tilling. Tilling and associated crop production likely result in the collapse of burrows and possibly direct mortality of TKR, as well as the removal of native vegetation, compaction of soil, and a reduction in microtopography. Thus, actively farmed land is unsuitable for TKR but once tilling and farming are discontinued, then TKR potentially can recolonize a site, particularly if there is adjacent occupied habitat. Recolonization of former agricultural lands has been observed among other kangaroo rat species (e.g., giant kangaroo rats $[D$. ingens]); U.S. Bureau of Land Management 2010) and at least one of our surveyed sites with TKR had evidence of past tilling. Habitat restoration might accelerate the recovery of previously farmed lands to suitable habitat for TKR.

Some survey sites, particularly in the northern portion of the range, had dense ground cover largely consisting of non-native grasses (e.g., red brome [Bromus madritensis], ripgut brome [Bromus diandrus]). TKR have previously been documented on some of these sites (e.g., Allensworth Ecological Reserve, Naval Air Station-Lemoore), but were not detected during our surveys. Most of the sites where we detected TKR had sparse ground cover. Dense ground cover renders habitat less suitable for TKR as it inhibits movements and increases predation risk (Williams and Germano 1992; Germano et al. 2001). Vegetation management may be necessary to enhance suitability on sites with dense ground cover. Such management is more likely to be necessary in the northern portion of TKR range where precipitation tends to be higher due to a north-south precipitation gradient in the San Joaquin Valley (Germano et al. 2011). Livestock grazing would be the most practical and effective strategy to reduce ground cover to more suitable levels for TKR (Williams and Germano 1992; Germano et al. 2001, 2011).

Our assessment of habitat attributes was coarse-scale. The assessments were rapid and qualitative, and they characterized entire sites. Thus, if suitable TKR habitat is defined by more subtle differences among attributes, we were less likely to detect them. Also, other factors that we did not assess (e.g., soil characteristics, flooding frequency, predator abundance) might influence the presence of TKR. Finally, past events also might determine whether TKR are present at a given site regardless of habitat suitability. Several of the sites we surveyed appeared to have suitable habitat but TKR were not detected. Many of the remaining parcels of TKR habitat are relatively small and also are isolated due to habitat fragmentation. Past events, such as flooding or rodenticide use, could have extirpated TKR from a site. Flooding was previously mentioned as the likely cause of TKR extirpation at Pixley National Wildlife Refuge and Allensworth Ecological Reserve, and also likely caused the extirpation of closely related Fresno kangaroo rats (D. n. exilis) from the Alkali Sink 
Ecological Reserve (Williams and Germano 1992). Lack of connectivity of many sites to other occupied habitat would preclude recolonization following extirpation events. Thus, some sites with suitable habitat may not be currently occupied by TKR. Such sites may be good candidates for reintroductions of TKR.

Another important habitat attribute is the presence of competitors. Competition between larger HKR (56-74 g; Jameson and Peeters 1988) and smaller TKR (35-38 g; USFWS 1998) has long been suspected (Williams and Germano 1992; USFWS 1998), but evidence for such competition has been limited. Tennant and Germano (2013) documented a 500\% increase in TKR on a plot from which HKR had been removed whereas no increase in TKR was observed on an associated control plot. Our results provided further evidence for competitive interactions between HKR and TKR. At sites with TKR, HKR were more likely to not be detected. HKR abundance was lower on average on sites with TKR, and HKR and TKR abundance were inversely related. These results suggest that HKR engage in interference competition with TKR. However, we also cannot dismiss an alternative hypothesis that habitat preferences of the two species are sufficiently dissimilar such that attributes more optimal for TKR are less optimal for HKR, and that this might be the reason at least in part for the inversely related abundance. Regardless of whether it is competition or habitat attributes, sites where HKR are abundant seem to be less suitable for TKR.

\section{Habitat Suitability Modeling}

We used the best available information on TKR occurrence and habitat attributes in developing our habitat suitability model. However, we caution that as with any suitability model, the results do not guarantee that TKR are present on a parcel. Instead, modeling results should be viewed as an estimate of the potential for TKR to occur on given lands; higher suitability rankings indicate a higher probability of TKR occurrence. Surveys are the only sure way to determine whether TKR are present on a parcel.

Our model results indicated that approximately 90,000 ha of habitat of any suitability remained throughout the range of TKR. Of that 90,000 ha, about 40,000 ha are highly degraded (e.g., recent farmland) and/or fragmented and are considered low quality (Rank 4). Around 20,000 ha have dense herbaceous ground cover or lack scalds and are considered medium quality habitat (Rank 3). The remaining 30,000 ha are what we considered moderately high to high quality habitat (Rank 1 or 2) consisting of alkali sink habitat that was less-disturbed, less fragmented, and less-densely vegetated. The 5-year review conducted for TKR indicated that 24,270 ha of habitat remained as of 1985, although the methods for this estimation are not provided (USFWS 2010). Our analysis indicates that more habitat may remain, but probably not in sufficient quantity to assure the continued existence of TKR in perpetuity.

Some of the remaining good quality habitat occurs in relatively large patches (Fig. 3). Such areas include the Coles Levee Ecosystem Preserve region, Semitropic Ridge region, and Lokern region (east of the California Aqueduct) in Kern County. Other large blocks of habitat are present farther to the northeast near the Kern-Tulare County line and in southern Tulare County. Most of these northeastern lands are owned by either CDFW (e.g., Allensworth Ecological Reserve) or USFWS (e.g., Pixley National Wildlife Refuge). However, TKR were detected on few of these lands during recent surveys. Many of these more northern sites have dense ground cover, consisting largely of non-native grasses. These sites will require active vegetation management to improve or maintain suitability. Some of 
these northern sites also have chronic flooding issues related to diversions of natural water flows, and this issue will need to be resolved as well.

Fortunately, many of the remaining lands with highly suitable habitat are conserved and owned/managed by conservation organizations (e.g., CDFW, USFWS, CNLM). Large blocks of highly suitable habitat on private lands occur in the Goose Lake region in Kern County and just south of the Tulare Lakebed on the Tulare-Kern County boundary (Fig. 3). These areas should be targeted for habitat protection. Additionally, lands with lower quality habitat that link patches with higher quality habitat also should be targeted for conservation. Due to their small size, TKR have limited capacity to cross large stretches of unsuitable habitat (e.g., active agricultural lands, industrial developments, urban areas) and habitat linkages would facilitate recolonizations, as well as demographic and genetic exchange.

\section{Conclusions and Recommendations}

Based on our surveys and information provided by colleagues, TKR were still present at many locations throughout their historic range (Fig. 4). Some of these locations comprised relatively large blocks of habitat whereas other locations consisted of relatively small parcels without connections to other occupied habitat. Continuing loss of natural habitat, some of which was observed during this study, is reducing the number of sites with TKR as well as further isolating populations through habitat fragmentation. Small, isolated populations are more vulnerable to extirpation via stochastic demographic, environmental, or catastrophic processes (Frankham et al. 2017). Thus, goals for TKR conservation should include conserving as much of the remaining higher quality habitat as possible, expanding buffers around occupied habitat, and increasing connectivity between habitat patches.

We offer the following recommendations based on our results:

1. Conduct additional surveys for TKR, particularly on lands that have not been surveyed in the past 20 years.

2. Conserve unprotected lands where TKR have been detected or that have high quality habitat based on suitability modeling.

3. Manage vegetation if necessary (e.g., grazing) on lands with extant or recent TKR populations to improve or maintain suitability.

4. Restore previously disturbed lands to render them suitable for TKR.

5. Translocate TKR from appropriate source populations to restored habitat or unoccupied conserved parcels with suitable habitat. Opportunities for the latter currently exist. However, additional research on effective translocation strategies is necessary first as past TKR translocations have had poor success (Germano 2001, 2010; Germano et al. 2013; Tennant et al. 2013).

\section{ACKNOWLEDGMENTS}

This project was funded by the CDFW with funds from the USFWS, Endangered Species Conservation and Recovery Grant Program. We thank John Battistoni and Krista Tomlinson at CDFW for administrative assistance and project support. For access to various parcels to conduct surveys, we thank Nick Stanley (USFWS), Jim Jones (South Valley Biology), Kern Water Bank Authority, and Amy Kuritsubo (U.S. Bureau of Land Management). Jim Jones of South Valley Biology and Greg Warrick of CNLM kindly shared unpublished trapping data. 


\section{LITERATURE CITED}

Best, T. L. 1991. Dipodomys nitratoides. Mammalian Species 381:1-7.

Blaustein, A. R., and A. C. Risser, Jr. 1976. Interspecific interactions between three sympatric species of kangaroo rats (Dipodomys). Animal Behaviour 24:381-385.

Brown, J. H., and J. C. Munger. 1985. Experimental manipulation of a desert rodent community: food addition and species removal. Ecology 66:1545-1563.

California Department of Conservation (CDOC), Farmland Mapping and Monitoring Program (FMMP). 2012. Important Farmland. Geospatial Data (1:24,000). Available from: www.conservation.ca.gov/dlrp/FMMP (Accessed: April 2020).

California Department of Water Resources (CDWR). 2012. Land Use Survey Data. Geospatial data $(1: 24,000)$. Available from: http://landwateruse.water.ca.gov/basicdata/landuse/landusesurvey.cfm (Accessed: April 2020).

Frankham, R., J. D. Ballou, K. Ralls, M. D. B. Eldridge, M. R. Dudash, C. B. Fenster, R. C. Lacy, and P. Sunnucks. 2017. Genetic Management of Fragmented Animal and Plant Populations. Oxford University Press, Oxford, UK.

Frye, R. J. 1983. Experimental field evidence of interspecific aggression between two species of kangaroo rat (Dipodomys). Oecologia 59:74-78.

Germano, D. J. 2001. Assessing translocation and reintroduction as mitigation tools for Tipton kangaroo rats (Dipodomys nitratoides nitratoides). Transactions of the Western Section of The Wildlife Society 37:71-76.

Germano, D. J. 2010. Survivorship of translocated kangaroo rats in the San Joaquin Valley, California. California Fish and Game 96:82-89.

Germano, D. J., G. B. Rathbun, L. R. Saslaw. 2001. Managing exotic grasses and conserving declining species. Wildlife Society Bulletin 29:551-559.

Germano, D. J., G. B. Rathbun, L. R. Saslaw, B. L. Cypher, E. A. Cypher, and L. Vredenburgh. 2011. The San Joaquin Desert of California: ecologically misunderstood and overlooked. Natural Areas Journal 31:138-147.

Germano, D. J., L. R. Saslaw, P. T. Smith, and B. L. Cypher. 2013. Survival and reproduction of translocated Tipton kangaroo rats in the San Joaquin Valley, California. Endangered Species Research 19:265-276.

Griggs, F. T., J. M. Zaninovich, and G. D. Werschkull. 1992. Historic native vegetation map of the Tulare Basin, California. Pages 111-118 in D.F. Williams, S. Byrne, and T.A. Rado, editors. Endangered and Sensitive Species of the San Joaquin Valley, California. California Energy Commission, Sacramento, CA, USA.

Jameson, E. W., Jr., and H. J. Peeters. 1988. California Mammals. University of California Press, Berkeley, CA, USA.

Kelly, P. A., S. E. Phillips, and D. F. Williams. 2005. Documenting ecological change in time and space: the San Joaquin Valley of California. Pages 57-78 in E.A. Lacey and P. Myers, editors. Mammalian Diversification: From Chromosomes to Phylogeography. Publications in Zoology Series, University of California Press, Berkeley, CA, USA.

National Oceanic and Atmospheric Administration (NOAA). 2002. Local climatological data, Bakersfield, California. National Climatological Data Center, Ashville, NC, USA.

Perri, L. M., and J. A. Randall. 1999. Behavioral mechanisms of coexistence in sympatric species of desert rodents, Dipodomys ordii and D. merriami. Journal of Mammal- 
ogy 80:1297-1310.

Reichman, O. J., and M. V. Price. 1993. Ecological aspects of heteromyid foraging. Pages 539-574 in H. H. Genoways, and J. H. Brown, editors. Biology of the Heteromyidae. American Society of Mammalogists, Special Publication 10, Provo, UT, USA.

Social Science Statistics. 2020. Statistics calculators. Available from: http:/www.socscistatistics.com/tests/Default.aspx (Accessed: April 2020).

Tennant, E. N., and D. J. Germano. 2013. Competitive interactions between Tipton and Heermann's kangaroo rats in the San Joaquin Valley, California. Southwestern Naturalist 58:258-264.

Tennant, E. N., D. J. Germano, and B. L. Cypher. 2013. Translocating endangered kangaroo rats in the San Joaquin Valley of California: recommendations for future efforts. California Fish and Game 99:90-103.

U.S. Bureau of Land Management (BLM). 2010. Carrizo Plain National Monument approved resource management plan and record of decision. U.S. Bureau of Land Management, Bakersfield, CA, USA.

U. S. Fish and Wildlife Service (USFWS). 1998. Recovery plan for upland species of the San Joaquin Valley, California. United States Fish and Wildlife Service, Portland, OR, USA.

U.S. Fish and Wildlife Service (USFWS). 2010. Tipton kangaroo rat (Dipodomys nitratoides nitratoides) 5-year review: summary and evaluation. United States Fish and Wildlife Service, Sacramento, CA, USA.

U.S. Geological Survey (USGS). 2007. Enhanced historical land-use and land-cover data sets of the U.S. Geological Survey. Geospatial Data (1:250,000). Available from: http://pubs.usgs.gov/ds/2006/240/ (Accessed: April 2020).

U.S. Geological Survey (USGS). 2013. Web-Enabled Landsat Data V1.5 5 year land cover change product, peak growing season bare ground cover per $30 \mathrm{~m}$ pixel. Geospatial data $(1: 100,000)$. Available from: http://globalmonitoring.sdstate.edu/projects/weld/ (Accessed: April 2020).

Williams, D. F., and D. J. Germano. 1992. Recovery of endangered kangaroo rats in the San Joaquin Valley, California. Transactions of the Western Section of The Wildlife Society 28:93-106.

Zar, J. H. 1984. Biostatistical Analysis. Prentice-Hall, Inc., Englewood Cliffs, NJ, USA.

Submitted 24 June 2020

Accepted 31 July 2020

Associate Editor was K. Smith 